\title{
Producción de Plántulas de Papa a Partir de Técnicas Combinadas de Micropropagación e Hidroponía para la Obtención de Semilla Prebásica
}

\author{
Susana Rigato, Adriana González, Marcelo Huarte ${ }^{1}$
}

\begin{abstract}
Resumen
Se estudió la multiplicación de plántulas de papa empleando técnicas de micropropagación en un sistema semejante a los utilizados en hidroponía.
\end{abstract}

Se utilizaron segmentos uninodales de plántulas obtenidas por micropropagación, los que se cultivaron autotróficamente, sin agregar sacarosa ni reguladores del crecimiento; para ello fue necesario evaluar contenedores descartables, substratos y soluciones nutritivas. Además, se buscó un método que permitiera la propagación de las plántulas obtenidas autotróficamente, para lo cual se evaluaron microesquejes de distinta ubicación en la planta madre según su capacidad de regeneración y adaptabilidad al trasplante.

Los segmentos, plantados en vermiculita en cajas de polipropileno y regados con solución nutritiva hidropónica, enraizaron a los 7 días y a los 15 días desarrollaron una plántula de varios nudos, con buen tamaño y vigor como para ser trasplantados en invernadero. Este crecimiento se comprobó en 10 variedades comerciales de papa. Los esquejes de los cortes sucesivos se plantaron en substrato a base de turba (Sphagnum). Tanto los esquejes apicales como los esquejes medios enraizaron sin la necesidad de aplicar reguladores del crecimiento; además las plántulas cortadas rebrotaron, optimizándose el uso del material utilizado. Las plántulas obtenidas autotróficamente presentaron un aspecto morfológico distinto a las obtenidas comúnmente in vitro, siendo aquéllas de baja altura, pero de tallos robustos y hojas anchas.

Los envases descartables, el substrato económico y el uso de bajas cantidades de una simple solución de hidroponía, sumado a la

\footnotetext{
${ }^{1}$ Estación Experimental Agraria INTA Balcarce, Casilla 276 , (7620) Balcarce.

Argentina. Correo electrónico: srigato@balcarce.inta.gov.ar
} 
disminución de posibles pérdidas por contaminación y trasplante, contribuyeron a que el sistema resultara una alternativa muy práctica y de bajo costo para la producción de plántulas de papa. Se presentan evidencias estadísticas del crecimiento en los diferentes sistemas.

Palabras claves adicionales: $\quad \begin{gathered}\text { Crecimiento fotoautotrófico, } \\ \text { micropropagación, Solanum } \\ \text { tuberosum, producción de } \\ \text { minitubérculos. }\end{gathered}$

\title{
Production of Potato Plantlets from Combined Micropropagation and Hidroponic Techniques to Obtain Pre-basic Seed
}

\begin{abstract}
Summary
Studies on potato plantlet multiplication were conducted by combining micropropagation and hydroponic techniques. Nodal cuttings from micropropagated plantlets were excided and cultivated in a photoautotrophic hydroponic system, without sacarose and in absence of growth regulators. It was necessary to evaluate different disposable containers, root media and nutrient solutions.
\end{abstract}

A method to continue propagation of the plants obtained by the new system was also developed. The regeneration ability of the cuttings from different parts of the photoautotrofic obtained plants was also evaluated.

Nodal cuttings growing on vermiculite with hydroponic nutrient solution in polypropylene boxes rooted after 7 days. A vigorous plant with several nodes, of enough size to be transplanted to the greenhouse, were obtained after 15 days. This type of growth was observed with 10 commercial potato varieties.

Successive cuttings were planted in a sphagnum moss rooting media. The apical cuttings as well as node cuttings from the rest of the plants rooted easily without growth regulating substances. 
These photoautotrophic produced plantlets showed short but vigorous stems and wider leaves than the conventional in vitro plants.

The use of disposable containers, low cost media and low quantities of a very simple hydroponic solution plus a reduction on the material lost due to contamination and to transplant, made this system a very easy to use and a low cost alternative to produce potato plantlets.

Additional Index words:

Photoautotrophic growth, micropropagation, Solanum tuberosum, minituber production.

\section{Introducción}

En la multiplicación de plántulas in vitro de papa (micropropagación) se utilizan medios nutritivos que incluyen sacarosa y reguladores del crecimiento. Uno de los problemas comunes en los laboratorios de cultivos in vitro comerciales y de investigación, es la contaminación del medio con microorganismos. (Liefert et al., 1992; Reed et al., 1994) Esto no sólo afecta el crecimiento y la sanidad de las plántulas sino que repercute en el ya elevado costo de producción de estos laboratorios. El uso de antibióticos en el medio no ha resultado una solución práctica debido a que se han observado efectos fitotóxicos. (Lizárraga et al., 1991; Gilbert J. E et al., 1991). Kozai et al. (1992) investigaron las condiciones ambientales dentro de los envases comúnmente utilizados en cultivos in vitro y determinaron que controlando el micro ambiente se logra favorecer el crecimiento y desarrollo de las plántulas, reducir los desórdenes fisiológicos, evitar pérdidas por contaminación y facilitar la aclimatación durante el trasplante de papa y otros cultivos, lo que llevaría a una reducción del costo de producción. Estos autores observaron que se pueden regenerar plántulas de papa por medios autotróficos debido a que los segmentos y las plántulas obtenidas poseen una alta capacidad para fotosintetizar.

El objetivo de este trabajo fue desarrollar un método de propagación rápido basado en los conceptos de un cultivo autotrófico que favoreciera el crecimiento de las plántulas de papa y además, redujera al mínimo las pérdidas debido a la contaminación y al shock de trasplante. 


\section{Materiales y Métodos}

En una primera fase se evaluaron envases, substratos y soluciones nutritivas, de bajo costo y muy prácticos, que permitieran el crecimiento autotrófico del material y en donde se manifestaran las ventajas citadas de esta técnica. En una segunda etapa se buscó un método que permitiera el repique de las plántulas obtenidas autotróficamente, para lo cual se evaluaron microesquejes de distinta ubicación en la planta madre según su capacidad de regeneración, adaptabilidad al trasplante y producción de minitubérculos.

\section{Materiales}

Se utilizaron plántulas in vitro obtenidas según los protocolos recomendados por CIP (Lizárraga $\mathrm{R}$, et al., 1991) las que se micropropagaron en tubos de ensayo $(10 \mathrm{~cm} \times 15 \mathrm{~mm})$ conteniendo $4 \mathrm{~mL}$ de medio. Durante la primera etapa se trabajó con las variedades Spunta y Kennebec y se corroboraron los resultados obtenidos en otros 10 cultivares. En la segunda parte se trabajó con la variedad Frital INTA.

\section{Métodos}

\section{Desarrollo del sistema autotrófico para enraizamiento y crecimiento de microesquejes uninodales.}

Se obtuvieron segmentos de un nudo (microesquejes uninodales) de plántulas in vitro de 20 días de crecimiento los cuales se plantaron en cajas plásticas descartables. Se comparó el crecimiento y desarrollo de los microesquejes en dos clases de cajas fabricadas con distintos materiales (polipropileno y acetato), dos tipos de substratos inertes (vermiculita y esponja vegetal) y dos soluciones nutritivas sin sacarosa ni reguladores de crecimiento (solución hidropónica SNH y medio MS líquido). La descripción de los elementos utilizados y condiciones de cultivo se presenta en la Tabla 1. A los 7 y 15 días se midió el crecimiento de la parte aérea (altura de los segmentos), tasa de multiplicación (segmentos nuevos producidos/esqueje trasplantado) y las pérdidas por contaminación. Se establecieron 8 tratamientos con 3 repeticiones (Tabla 2). El sistema que produjo el mejor crecimiento de los microesquejes, se verificó con otros10 cultivares para los que se plantaron 24 microesquejes/cultivar. 
Tabla 1. Descripción de las condiciones de cultivo para el desarrollo del sistema con microesquejes

\begin{tabular}{|c|c|}
\hline Material vegetal: & $\begin{array}{l}\text { Segmentos uninodales de plántulas in } \\
\text { vitro de papa de las variedades Spunta y } \\
\text { Kennebec. }\end{array}$ \\
\hline $\begin{array}{l}\text { Cantidad de plántulas: } \\
\text { Medios de cultivo: }\end{array}$ & $\begin{array}{l}\text { Cajas A (de polipropileno, para } \\
\text { microondas marca Cotnyl } 122 \text { con tapa, } \\
\text { de } 14 \times 10 \times 4 \mathrm{~cm} \text { ) con vermiculita. } \\
\text { Cajas B (de acetato transparente tipo } \\
\text { cristal, marca Rostell, redondas de } \\
\text { diámetro } 10 \mathrm{~cm} \text { ) con esponja vegetal. } \\
\text { Caja A: } 24 \text { esquejes } \\
\text { Caja B: } 12 \text { esquejes } \\
\text { MS líquido, sin sacarosa. (Murashige- } \\
\text { Skoog, MSSigma 5519) } \\
\text { SNH (solución hidropónica, Evans y } \\
\text { Nason, 1953) } \\
70 \text { ml/contenedor }\end{array}$ \\
\hline Condiciones de cultivo: & $\begin{array}{l}\text { Luz: } 60 \text { micromoles.m }{ }^{2} \cdot \sec ^{-1} \text { aportados } \\
\text { por tubos fluorescentes "cool white", } \\
\text { fotoperíodo de } 16 \mathrm{hr} \text {. } \\
\text { Temperatura: } 24^{\circ} \mathrm{C}\end{array}$ \\
\hline Diseño estadístico & $\begin{array}{l}\text { Factorial aleatorizado, } 8 \text { tratamientos } \\
\text { con } 3 \text { repeticiones (Tabla2). Análisis: } \\
\text { Programa SAS Instituto Inc. }\end{array}$ \\
\hline
\end{tabular}

Tabla 2. Descripción de los tratamientos.

\begin{tabular}{|c|c|c|c|}
\hline Tratamiento & Contenedor & Soporte & Medio \\
\hline $\begin{array}{l}1 \\
2\end{array}$ & \multirow{2}{*}{$\begin{array}{l}\text { Bandeja de } \\
\text { Polipropileno } \\
\text { (A) }\end{array}$} & Esponja & $\begin{array}{l}\text { Soluc. Hidropónica (SNH) } \\
\text { Medio M.S. (MS) } \\
\end{array}$ \\
\hline $\begin{array}{l}3 \\
4 \\
\end{array}$ & & Vermiculita & $\begin{array}{l}\text { Soluc. Hidropónica(SNH) } \\
\text { Medio M.S. (MS) }\end{array}$ \\
\hline $\begin{array}{l}5 \\
6\end{array}$ & \multirow{2}{*}{$\begin{array}{l}\text { Bandeja de } \\
\text { Acetato } \\
\text { (B) }\end{array}$} & Esponja & $\begin{array}{l}\text { Soluc. Hidropónica(SNH) } \\
\text { Medio M.S. (MS) }\end{array}$ \\
\hline $\begin{array}{l}7 \\
8\end{array}$ & & Vermiculita & $\begin{array}{l}\text { Soluc. Hidropónica(SNH) } \\
\text { Medio M.S. (MS) }\end{array}$ \\
\hline
\end{tabular}




\section{Repiques sucesivos y trasplante de plántulas obtenidas de microesquejes de distintas alturas del tallo de la planta madre, cultivados en sistema autotrófico hidropónica.}

Se cortaron plántulas in vitro (de 20 días) separando los esquejes obtenidos según su posición a lo largo del tallo en esquejes apicales, medios y básales los que se plantaron en cajas separadas (40 esquejes por caja de polipropileno). Los esquejes basales se cortaron de manera que mantuvieran parte de las raíces. En este ensayo se utilizaron dos tipos de substrato: vermiculita y Humosoil (substrato comercial a base de turba). Ambos substratos se regaron con Solución Nutritiva Hidropónica $(\mathrm{SNH})$. A los 15 días, las plántulas obtenidas en las cajas se repicaron nuevamente en segmentos uninodales los que se plantaron separados según fueran apicales o medios y se regaron con SNH y con SNH con agregado de $0.1 \mathrm{mg} / \mathrm{l}$ de ácido giberélico. Se establecieron 8 tratamientos con 3 repeticiones por tratamiento. Los segmentos básales que resultaron al cortar los ápices y medios, se dejaron en el mismo contenedor y se regaron con el fin de observar su rebrote. Los esquejes se cultivaron durante 15 días a $23^{\circ} \mathrm{C}$, y 16 horas fotoperíodo (60 micromoles. $\mathrm{m}^{-2} \cdot \mathrm{sec}^{-1}$ ).

\section{Resultados}

Los segmentos tanto de la variedad Spunta como de Kennebec plantados en vermiculita en las cajas de polipropileno y regados con solución nutritiva hidropónica enraizaron a los 7 días y a los 15 días desarrollaron una plántula de varios nudos, con buen tamaño y vigor como para ser trasplantable en invernadero. Los segmentos que fueron cultivados en las cajas de acetato transparente no enraizaron y no crecieron ni desarrollaron nuevos nudos. En las Tablas 3 y 4 se comparan los datos de los tratamientos realizados en las cajas de polipropileno. En ninguno de los 8 tratamientos se observó contaminación. Las plántulas obtenidas en los tratamientos con vermiculita presentaron un aspecto morfológico distinto a las obtenidas comúnmente in vitro, siendo aquellas de baja altura pero de tallos robustos y hojas anchas. Este crecimiento se comprobó en 10 variedades comerciales de papa. Los 24 microesquejes plantados de cada variedad enraizaron, no existieron pérdidas por contaminaciones ni mortandad, y a los 20 días habían desarrollado una plántula con vigor suficiente para trasplantar al invernadero (Tabla 5). 
Tabla 3. Crecimiento y tasa de multiplicación de esquejes uninodales de la variedad Spunta en los tratamientos realizados en cajas de polipropileno.

\begin{tabular}{|c|lccc|}
\hline Tratamiento & Tipo de soporte & $\begin{array}{c}\text { Solución } \\
\text { nutritiva }\end{array}$ & $\begin{array}{c}\text { Altura } \\
(\mathrm{cm})\end{array}$ & TM* $^{*}$ \\
\hline 1 & Esponja & SNH & $0.87 \mathrm{a}$ & $0.73 \mathrm{a}$ \\
2 & Esponja & MS & $0.54 \mathrm{a}$ & $0.49 \mathrm{a}$ \\
3 & Vermiculita & SNH & $4.29 \mathrm{~b}$ & $3.70 \mathrm{~b}$ \\
4 & Vermiculita & MS & $2.41 \mathrm{c}$ & $2.33 \mathrm{c}$ \\
\hline
\end{tabular}

* TM: tasa de multiplicación o segmentos nuevos producidos / esqueje trasplantado.

Nota: Los valores representan el promedio de tres repeticiones con 24 esquejes cada una; las letras iguales a continuación de las medias significan que no hubo diferencias significativas entre tratamientos.

Tabla 4. Crecimiento y tasa de multiplicación de esquejes uninodales de la variedad Kennebec en los tratamientos realizados en cajas de polipropileno.

\begin{tabular}{|l|lccc|}
\hline Tratamiento & Tipo de soporte & $\begin{array}{c}\text { Solución } \\
\text { nutritiva }\end{array}$ & $\begin{array}{c}\text { Altura } \\
(\mathrm{cm})\end{array}$ & TM$^{*}$ \\
\hline 1 & Esponja & SNH & $0.53 \mathrm{a}$ & $0.49 \mathrm{a}$ \\
2 & Esponja & $\mathrm{MS}$ & $0.48 \mathrm{a}$ & $0.46 \mathrm{a}$ \\
3 & Vermiculita & SNH & $2.39 \mathrm{~b}$ & $2.58 \mathrm{~b}$ \\
4 & Vermiculita & $\mathrm{MS}$ & $1.47 \mathrm{c}$ & $1.72 \mathrm{c}$ \\
\hline
\end{tabular}

*TM: tasa de multiplicación o segmentos nuevos producidos / esqueje trasplantado.

Nota: Los valores representan el promedio de tres repeticiones con 24 esquejes cada una; las letras iguales a continuación de las medias significan que no hubo diferencias significativas entre tratamientos.

Para los análisis estadísticos se utilizó el programa estadístico SAS (SAS Instituto Inc.) por medio del cual se realizaron los análisis de varianza y de comparación de medias (Test de Duncan). 
Tabla 5. Crecimiento de los microesquejes de 15 variedades comerciales de papa plantados en cajas de polipropileno y vermiculita regados con solución hidropónica, a los 7, 14 y 21 días de la siembra.

\begin{tabular}{|l|lll|lll|}
\hline \multirow{2}{*}{ Cultivar } & \multicolumn{3}{c|}{ Altura (cm) } & \multicolumn{3}{c|}{ TM (cant.) } \\
\cline { 2 - 7 } & 7 días & 14 días & 21 días & 7 días & 14 días & 21 días \\
\hline Frital INTA & 0.50 & 3.00 & 4.00 & 2.01 & 4.00 & 4.00 \\
Araucana INTA & 0.83 & 1.50 & 2.79 & 0.94 & 2.46 & 2.92 \\
Shepody B & 1.23 & 2.08 & 3.67 & 1.38 & 2.46 & 3.29 \\
78.502.5 & 0.92 & 1.23 & 1.54 & 1.04 & 1.63 & 1.75 \\
Serrana INTA & 1.1 & 1.67 & 2.60 & 1.81 & 3.04 & 3.50 \\
Huinkul MAG & 1.08 & 1.92 & 1.96 & 1.38 & 2.40 & 2.50 \\
Primicia INTA & 1.15 & 2.15 & 2.71 & 1.60 & 3.67 & 3.63 \\
Spunta & 1.95 & 3.98 & 5.04 & 2.92 & 4.46 & 4.63 \\
Kennebec & 1.42 & 2.13 & 2.88 & 3.71 & 3.33 & 3.38 \\
Calen INTA & 0.88 & 1.81 & 1.83 & 0.88 & 2.29 & 3.58 \\
Keluné INTA & 0.83 & 1.85 & 2.83 & 1.17 & 2.50 & 3.75 \\
Pampeana INTA & 1.46 & 3.25 & 3.71 & 1.77 & 2.96 & 3.96 \\
B 85.616.3 & 0.65 & 1.63 & 2.21 & 1.52 & 1.54 & 3.04 \\
\hline
\end{tabular}

Nota: Cada valor representa el promedio de 24 plántulas: altura $(\mathrm{cm})$ de las plántulas obtenidas, TM: tasa de multiplicación o segmentos nuevos producidos / esqueje trasplantado.

En la Tabla 6 se observa el resultado obtenido al realizar otra multiplicación de los esquejes obtenidos en distintos substratos. Se obtuvo un bajo porcentaje de enraizamiento en los esquejes propagados sucesivamente en vermiculita, mientras que en el substrato basado en turba se logró que tanto los ápices como los esquejes medios enraizaran en un $100 \%$.

Los esquejes básales de las plántulas de donde se obtuvieron los esquejes apicales y los medios, que se dejaron en el substrato, rebrotaron formando una nueva plántula que pudo volver a multiplicarse. Las plántulas obtenidas en substrato basado en turba presentaron buen tamaño y se propagaron sin inconvenientes no siendo necesaria la aplicación de reguladores del crecimiento. En los ápices propagados en substrato basado en turba se observó enraizamiento a partir de los primeros 5 días, obteniéndose plántulas listas para trasplantar a los 10 días de plantados mientras que las plántulas obtenidas de esquejes medios tardaron entre 13 y 15 días. 
Tabla 6. Porcentaje de esquejes apicales y medios que enraizaron regenerando una plántula apta para trasplante.

\begin{tabular}{|llc|cc|}
\hline & Tratamiento & & 7 días & 14 días \\
\hline $\begin{array}{l}\text { Origen del } \\
\text { esqueje }\end{array}$ & Tipo de substrato & AG* $^{*}$ & $\begin{array}{c}\text { \% esquejes } \\
\text { enraizados }\end{array}$ & $\begin{array}{c}\text { \%plántulas } \\
\text { obtenidas }\end{array}$ \\
\hline Ápice & Vermiculita & + & 32.99 & 53.66 \\
& Substrato & - & 60.19 & 65.83 \\
& Vermiculita & + & 99.13 & 100.00 \\
& & - & 99.13 & 100.00 \\
\hline Medio & Substrato & - & 6.30 & 16.50 \\
& & + & 8.80 & 10.80 \\
& & - & 87.20 & 100.00 \\
& & + & & 100.00 \\
\hline
\end{tabular}

AG*: agregado de ácido giberélico al $0.1 \mathrm{~g} / \mathrm{l}$ en la SNH.

Nota: Los valores representan el promedio de 120 esquejes.

\section{Discusión}

Estos resultados sugieren que, debido a que el crecimiento de los segmentos se obtiene sin agregar sacarosa ni reguladores del crecimiento, se puede realizar el último corte de plántulas, en cajas de polipropileno con vermiculita evitándose los riesgos de pérdidas de plántulas por problemas de contaminación a la vez que se disminuye el shock de trasplante cuando pasan al invernadero. El rápido enraizamiento y buen crecimiento de los microesquejes en los tratamientos en donde se emplean cajas de polipropileno con substrato basado en turba regados con solución nutritiva, hacen posible el corte sucesivo de estos materiales. De esta manera se puede realizar la multiplicación de plántulas de papa, de manera similar a la micropropagación, pero en un sistema semejante al utilizado en hidroponía. La amplitud de las cajas utilizadas puede haber contribuido al buen desarrollo de las plántulas debido a una humedad relativa no tan elevada y a un mayor intercambio gaseoso, factores favorables para una mayor capacidad fotosintética (Kubota C. y Kozai T., 1992). Es de suponer que por las características de las plántulas obtenidas en medios autotróficos, cuyas hojas son más gruesas, con mayor contenido de cera epicuticular y mayor cantidad de estomas funcionales que las obtenidas en sistemas convencionales (Zobayed et.al, 1998), el shock y las pérdidas ocasionadas por el trasplante serán mínimos. Además, estos contenedores, una vez trasladados al invernadero se pueden abrir unos 
días antes del trasplante para permitir una mayor rustificación de las plántulas sin que afloren bacterias y hongos en el substrato.

Los envases descartables, el substrato económico y el uso de bajas cantidades de una simple solución de hidroponía sumado a la disminución de posibles pérdidas por contaminación y trasplante, contribuyeron a que el sistema resultara muy práctico y de bajo costo.

Aún queda por determinar el efecto del tipo de esqueje que dio origen a las plántulas sobre la producción de minitubérculos; se iniciaron ensayos de rendimiento en minitubérculos comparando plántulas provenientes de microesquejes apicales, medios y basales producidos fotoautotróficamente con plántulas producidas por micropropagación.

\section{Referencias Bibliográficas}

1. Evans H.J.; Nason, A. 1953. Plant Physiology 28:233-254.

2. Gilbert. J.E.; Shohet S.; Caligari, P.D.S. 1991. The use of antibiotics to elimínate latent bacterial contamination in potato tissue cultures. Ann Appl. Biol. 119:113-120

3. Kozai, T. 1991. Autotrophic Micropropagation. En: Environmental Control in Micropropagation, Ed Byoung Ryong Jeong, Vol 1.

4. Kubota, C.; Kozai, T. 1992. Growth and net photosynthetic rate of Solanum tuberosum in vitro under forced and natural ventilation. HortScience27:1312-1314.

5. Leifert, C.; Waites, B.; Keetley, J.; Wright, S.; Nicholas, R.; Waites, M.W. 1994. Effect of medium acidification on filamentous fungí, yeasts and bacterial contaminants in Delphinium tissue cultures. Plant Cell, Tissue and Organ Culture 36:149-155.

6. Lizárraga, R.; Panta, A.; Jayasinghe, U.; Dodds, J. 1991. En: Cultivo de Tejidos para la Eliminación de Patógenos. Guía de investigación CIP No. 3, p. 11.

7. Reed, M. B.; Buckley, P.; De Wilde, T.N. 1995. Detection and eradication of endophytic bacteria from micropropagated mint plants. In Vitro Cell. Dev. Biol. 31:53-57. 
8. Zobayed, S.M.A.; Afreen-Zobayed, F.; Kubota, C.; Kozai, T. 1998. Stomatal characteristics and leaf anatomy of potato plantlets cultured in vitro under photoautotrophic and photomixotrophic conditions. En: Environmental Effects and Their Control in Plant Propagation and Transplant Production. Ed Michiko Abe, Vol 1, p 108. 